\title{
Establishment of Prediction Model of Microstructure and Properties of 3003 Aluminum Alloy during Hot Deformation
}

\author{
Guiqing CHEN ${ }^{1}$, Gaosheng FU $^{2}{ }^{*}$, Tianyun WEI ${ }^{1}$, Chaozeng CHENG ${ }^{2}$, Huosheng WANG ${ }^{3}$, \\ Lili SONG ${ }^{2}$
}

\author{
${ }^{1}$ Department of Mechanical Engineering, Fujian Chuanzheng Communications College, Fuzhou 350007, China \\ ${ }^{2}$ College of Materials Science and Engineering, Fuzhou University, Fuzhou 350108, China \\ ${ }^{3}$ College of Materials Science and Engineering, FuJian University of Technology, Fuzhou 350118, China \\ crossref http://dx.doi.org/10.5755/j01.ms.25.4.19436
}

Received 08 November 2017; accepted 05 July 2018

\begin{abstract}
The 3003 aluminum alloy was deformed by isothermal compression in the range of deformation temperature $300-500{ }^{\circ} \mathrm{C}$ at strain rate $0.01-10.0 \mathrm{~s}^{-1}$ with Gleeble- 1500 thermal simulator. A constitutive equation is established from the flow stress of the hot deformation. It is found that the average grain size of the 3003 aluminum alloy increases with the decrease of Zener-Hollomon $(Z)$ value, and there is a linear correlation between them. The prediction model of the steady-state flow stress and the average grain size is established. The steady-state flow stress increases with the decrease of the average grain size. The microhardness of the 3003 aluminum alloy has a positive linear relationship with $\ln Z$, and the relationship between the microhardness and the grain size meets the Hall-Petch equation, which can provide a reference for the microstructure control and rolling equipment selection of the 3003 aluminum alloy under hot deformation conditions.

Keywords: 3003 aluminum alloy, hot deformation, average grain size, steady-state flow stress, microhardness.
\end{abstract}

\section{INTRODUCTION}

With the development of computer technology and information technology, the prediction and control of the structure and property of the aluminum alloy during the rolling process has become one of the key technologies of modern integrated manufacturing $[1-3]$. The mathematic model describing the structure and performance is the basis for the accurate prediction and control of the microstructure and properties of the aluminum alloy during the production process, which has become the focus of attention $[4,5]$. E. Nes proposed a new approach to the modeling of work hardening during plastic deformation of f.c.c.-metals and alloys [6], Bouaziz O. reviewed that the relations between microstructure and mechanical properties is presented focusing on plasticity mechanisms, strain-hardening, yield stress, texture, fracture and fatigue [7]. But the systematic study of the relationship among the hot deformation flow stress, microhardness, deformation conditions, and the grain size, which plays an important role for the rolling equipment selection, rolling process parameters preparation and the final quality of the product is less reported. 3003 aluminum alloy has excellent comprehensive performance and is widely used. The research group recently conducted preliminary studies on the melt treatment and hot deformation of 3003 aluminum alloys. A close relationship between melt treatment and hot deformation was found $[8,9]$. In order to further improve the product quality of 3003 aluminum alloys, it is necessary to establish a predictive model between its microstructure and performance. Therefore, the thermal compression simulation experiment of the 3003 aluminum alloy was carried out by Gleeble-1500 thermal simulation test machine, for quantitative description of the relationship among microstructures, hot deformation conditions, the flow stress and microhardness of the alloy during hot deformation. Through the simulation of the microstructure evolution of the aluminum alloy and the prediction of the mechanical properties, the precise and quantitative control of the microstructure and properties of the aluminum alloy during the rolling process can be achieved, so as to optimize the rolling process and the composition of the alloy.

\section{EXPERIMENTAL PROCEDURES}

The main components of the 3003 aluminum alloy are (mass fraction, \%): $0.62 \mathrm{Fe}, 0.58 \mathrm{Si}, 1.09 \mathrm{Mn}, 0.068 \mathrm{Cu}$, $0.006 \mathrm{Ti}, 0.03 \mathrm{Mg}, 0.007 \mathrm{Ni}, 0.008 \mathrm{Zn}$, the balance being Al. The preparation of the ingot is: firstly, the aluminum ingots were subjected to the melt treatment in a graphite crucible resistance furnace. Secondly, pour out the ingot, heat treatment $\left(510^{\circ} \mathrm{C}, 20 \mathrm{~h}\right)$. Finally, cylindrical specimens of $10 \mathrm{~mm}$ in diameter and $15 \mathrm{~mm}$ in height were machined for hot compression tests. The both flat ends of the specimen were recessed to a depth of $0.2 \mathrm{~mm}$ deep around to entrap graphite powder in order to minimize the friction between the specimen surface and clamp. The samples were mounted on a Gleeble-1500 thermal simulator for isothermal constant strain rate hot compression test. The experimental conditions for the hot deformation are: the heating rate of the sample is controlled at $1{ }^{\circ} \mathrm{C} / \mathrm{s}$, insulation for 5 minutes after the set temperature. Control the amount

\footnotetext{
${ }^{*}$ Corresponding author. Tel.: +0086-18060360888.

E-mail address: fugaosheng@fzu.edu.cn (G. Fu)
} 
of compression deformation of 0.7 . The range of strain rate is $0.01 \sim 10.0 \mathrm{~s}^{-1}$, and the deformation temperature is in the range of $300 \sim 500{ }^{\circ} \mathrm{C}$. The data of the experiment is controlled and collected by the computer. The deformed specimens were quenched in water quickly after each compression test in order to maintain the microstructure.

The microstructure characterization of the deformed samples were observed by using XJG-05 optical microscope (OM). To take microscopic examination, the specimens were mechanically polished and etched with Keller's reagent $\left(2.5 \mathrm{ml} \mathrm{HNO}_{3}, 1.5 \mathrm{ml} \mathrm{HCl}, 1 \mathrm{ml} \mathrm{HF}\right.$ and $95 \mathrm{ml}$ $\mathrm{H}_{2} \mathrm{O}$ ). The grain size was measured by the linear intercept method. The microhardness of the deformed sample was tested. The load was $0.49 \mathrm{~N}$, and the load holding time was $30 \mathrm{~s}$. The average microhardness of the sample was averaged after 5 points were tested for each sample.

\section{RESULTS AND DISCUSSION}

\subsection{Establishment of the constitutive equation}

Fig. 1 shows the true stress-true strain curve of the 3003 aluminum alloy under different deformation conditions.

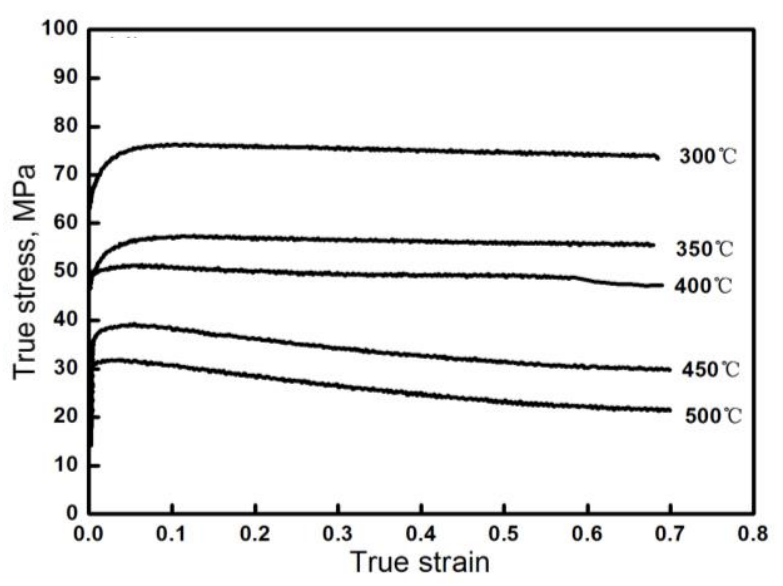

a

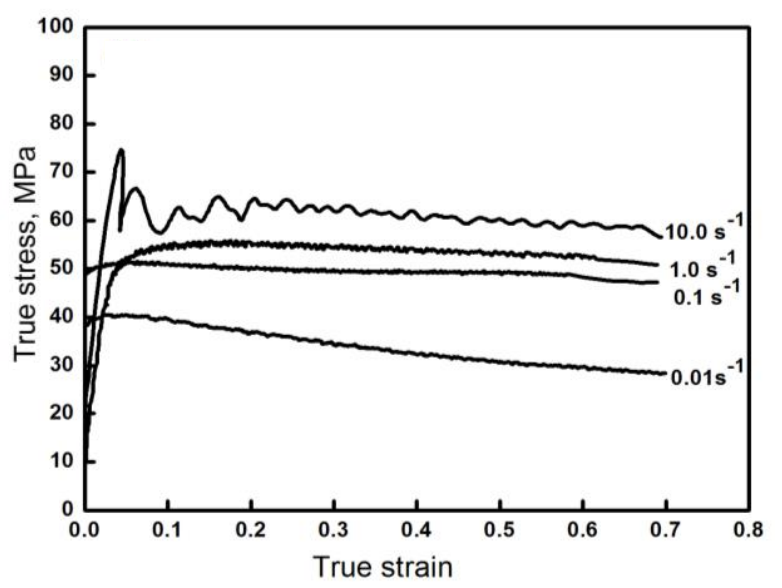

b

Fig. 1. True stress-strain curves of the 3003 aluminum alloy: $\mathrm{a}-0.1 \mathrm{~s}^{-1} ; \mathrm{b}-400{ }^{\circ} \mathrm{C}$

At the same strain rate, the flow stress decreases as the deformation temperature increases. When the deformation temperature is the same, the flow stress increases as the strain rate increases. It shows that the alloy is a strain rate sensitive material. If the strain exceeds a certain value, the flow stress tends to decrease as the strain increases, and the alloy may undergo dynamic recrystallization (DRX). Under high temperature and low strain rate conditions, the alloy undergoes DRX and is more likely to deform. When the strain rate reaches $10.0 \mathrm{~s}^{-1}$, the flow curves appear sawtooth fluctuations, indicating that discontinuous dynamic recrystallization occurred in the alloy at this time.

The deformation mechanism of the aluminum alloy is complicated at high temperature, and the alloy has the sensitivity of deformation temperature and strain rate. The true stress-true strain data under certain temperature and strain rate are usually collected by hot compression simulation experiment. Based on these data, material constants are calculated, and the constitutive equation is established. The peak flow stress of the material is an important characteristic parameter in the process of high temperature deformation, and the peak stress is one of the important process parameters to determine the material processing technology. Considering that the peak flow stress is at the moment when the strain is small, and the change of the peak stress before and after the the amendment of temperature rise is not obvious, so the constitutive equation is established by taking the true peak stress under the corresponding strain rate and deformation temperature conditions [10].

The peak flow stress of the alloy is assumed to be consistent with the hyperbolic sine mathematic model proposed by Sellars and Tegart $[11,12]$, that is

$\dot{\varepsilon}=A[\sinh (\alpha \sigma)]^{n} \exp (-Q / R T)$,

where $\dot{\varepsilon}$ is the strain rate, $\mathrm{s}^{-1} ; A$ is the constant, $a$ is the stress level parameters, $\mathrm{MPa}^{-1} ; \sigma$ is the flow stress, MPa; $n$ is the stress index, $Q$ is the deformation activation energy, $\mathrm{J} / \mathrm{mol}, R$ is the gas constant, $T$ is the deformation temperature.

Under low stress conditions $(\alpha \sigma<0.8)$, Eq. 1 can be transformed into a power exponent relationship:

$\dot{\varepsilon}=A_{1} \sigma^{n_{1}}$.

Under high stress conditions $(\alpha \sigma>1.2)$, Eq. 1 can be transformed into an exponential relationship:

$\dot{\varepsilon}=A_{2} \exp (\beta \sigma)$,

where $A_{1}, A_{2}, n_{1}, \beta$ do not change with the changes of deformation temperature, which are constant, and $\alpha=\beta / n_{1}$.

Assuming that the deformation activation energy can not be affected by the deformation temperature, both sides of Eq. 1, Eq. 2 and Eq. 3 were transformed respectively to obtain:

$$
\begin{aligned}
& \ln \dot{\varepsilon}=n \ln [\sinh (\alpha \sigma)]+\ln C ; \\
& \ln \dot{\varepsilon}=\ln A_{1}+n_{1} \ln \sigma ; \\
& \ln \dot{\varepsilon}=\ln A_{2}+\beta \sigma .
\end{aligned}
$$

Regression analysis was performed on the flow stress and strain rate according to Eq. 5 and Eq. to find $n_{1}$ and $\beta$, and $\alpha$ was obtained. Substitute $\alpha$ into Eq. 4 to find $n$. 
Table 1. Hot deformation material constant of the 3003 aluminum alloy

\begin{tabular}{|c|c|c|c|c|c|}
\hline$n_{1}$ & $\beta$ & $a, \mathrm{~mm}^{2} \mathrm{~N}$ & $n$ & $D$ & $Q, \mathrm{kJmol}^{-1}$ \\
\hline 12.51249 & 0.20923 & 0.01672 & 9.14086 & 2.42554 & 191.79623 \\
\hline
\end{tabular}

Table 2. $\ln Z$ value of the 3003 aluminum alloy under different deformation conditions

\begin{tabular}{|c|c|c|c|c|c|c|c|c|c|}
\hline$T,{ }^{\circ} \mathrm{C}$ & \multicolumn{3}{|c|}{400} & 300 & \multicolumn{2}{c|}{350} & 450 & 500 \\
\hline$\dot{\varepsilon} / \mathrm{s}^{-1}$ & 0.01 & 0.1 & 1.0 & 10.0 & & \multicolumn{3}{|c|}{0.1} \\
\hline $\operatorname{lnZ}$ & 29.67 & 31.98 & 34.28 & 36.58 & 37.96 & 34.73 & 29.60 & 27.54 \\
\hline
\end{tabular}

It can be obtained the function of the temperature and flow stress according to Eq. 1. Assuming that the hot deformation activation energy is constant over a certain hot deformation temperature range, and the strain rate remains constant, both sides of the Eq. 1 are transformed to obtain:

$\ln \dot{\varepsilon}+Q /(R T)=n \ln [\sinh (\alpha \sigma)]+\ln A ;$

$\ln [\sinh (\alpha \sigma)]=E+D \frac{1000}{T} ;$

$\ln Z=\ln \dot{\varepsilon}+Q / R T$,

where $E$ and $D$ are constants, $Z$ is a Zener-Hollomon parameter that can be used to describe the relationship between flow stress and deformation conditions during hot deformation of a material.

Substitute $\alpha$ into Eq. 8 to find $D$. Combining Eq. 7 and Eq. 8 , it can be inferred $D=Q / \mathrm{R} \cdot n$, thus the activation energy $(Q)$ is found. According to the Eq. 4 to Eq. 8, the material constants of the 3003 aluminum alloy can be calculated as shown in Table 1.

Therefore, the constitutive model of flow stress during high temperature deformation is:

$$
\begin{aligned}
& \dot{\varepsilon}=2.03 \times 10^{14} \sinh [0.01672 \times \sigma]^{9.14086} \\
& \cdot \exp (-191.79623 / R T)
\end{aligned}
$$

Under the experimental conditions, $\ln Z$ value of the 3003 aluminum alloy during hot deformation can be obtained by the Eq. 9, as shown in Table 2.

\subsection{Effect of hot deformation conditions on average grain size}

Fig. 2 shows the grain structure of the 3003 aluminum alloy under different deformation conditions. It can be seen that when $\ln Z=31.98$, as shown in Fig. 2 c, equiaxed recrystallized grains are produced around the elongated grains, and the grain boundaries begin to bend and appear jagged lines, indicating that partial dynamic recrystallization occurs. When $\ln Z=29.60$, the grain has become more rounded, and the grain boundary becomes clear, indicating that a more complete dynamic recrystallization has taken place, as shown in Fig. 2 b. When $\ln Z=25.24$, as shown in Fig. 2 a, the grain boundary is clear, and the grain has a tendency to grow up. From the above analysis it can be seen that when the $\ln Z$ value is small (high deformation temperature or low strain rate), the softening mechanism of the 3003 aluminum alloy is mainly dynamic recrystallization. When $\ln Z=42.56$, as shown in Fig. $2 \mathrm{f}$, the grain is flattened, and the microstructure is mainly composed of elongated grains in the vertical compression direction. When $\ln Z=39.33$, as shown in Fig. $2 \mathrm{e}$, the structure is mainly composed of deformed grains, grain boundary is relatively straight and small, and most of them are straight and blurred, so it is difficult to distinguish. That is, when the $\ln Z$ value is higher (the deformation temperature is low or the strain rate is large), the softening mechanism of the alloy is mainly dynamic recovery.

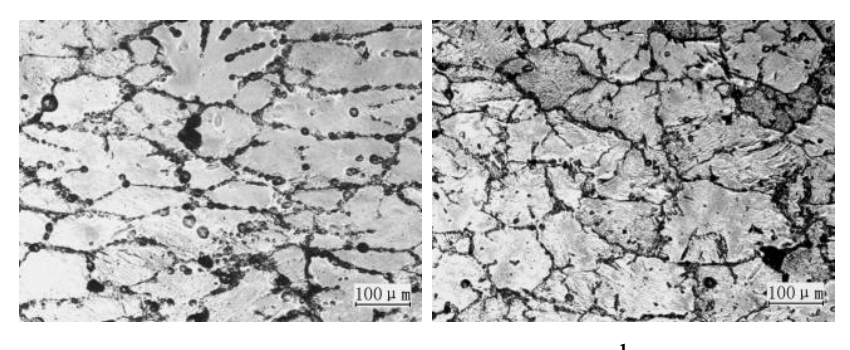

a b

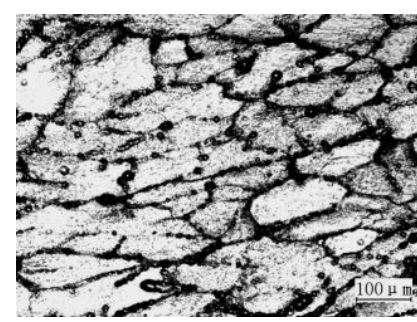

c

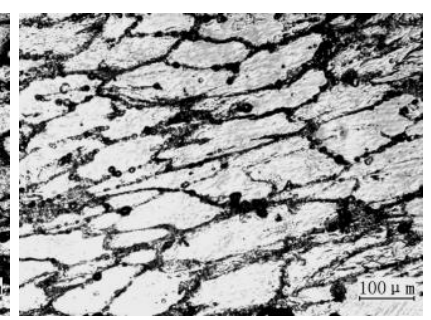

d

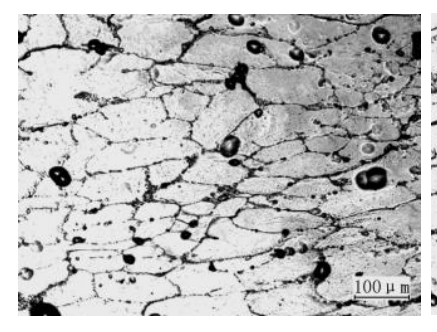

e

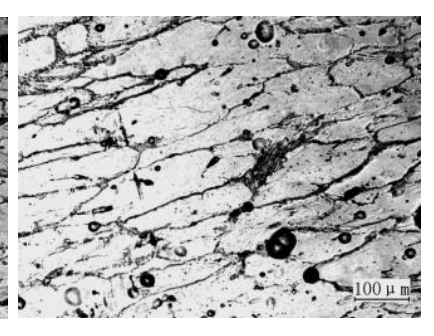

$\mathrm{f}$

Fig. 2. Microstructure of the 3003 aluminum alloy under different $\ln Z$ value: $\mathrm{a}-T=500{ }^{\circ} \mathrm{C}, \dot{\varepsilon}=0.01 \mathrm{~s}^{-1}(\ln Z=25.24)$; $\mathrm{b}-T=450{ }^{\circ} \mathrm{C}, \dot{\varepsilon}=0.1 \mathrm{~s}^{-1}(\ln Z=29.60) ; \mathrm{c}-T=400{ }^{\circ} \mathrm{C}$, $\dot{\varepsilon} \quad=0.1 \quad \mathrm{~s}^{-1}(\ln Z=31.98) ; \quad \mathrm{d}-T=400^{\circ} \mathrm{C}$, $\dot{\varepsilon} \quad=10.0 \quad \mathrm{~s}^{-1}(\ln Z=36.58) ; \quad \mathrm{e}-T=350^{\circ} \mathrm{C}$, $\dot{\varepsilon} \quad=10.0 \quad \mathrm{~s}^{-1}(\ln Z=39.33) ; \quad \mathrm{f}-T=300^{\circ} \mathrm{C}$, $\dot{\varepsilon}=10.0 \mathrm{~s}^{-1}(\ln Z=42.56)$

Through the observation and analysis of the microstructure of the alloy, the three-dimensional relationship diagram among the grain size $\left(d_{\mathrm{ave}}\right)$, the strain rate and the deformation temperature was established, as shown in Fig. 3. As can be seen from Fig. 3, the average grain size increases as the strain rate decreases or the deformation temperature increases. For the softening process of dynamic recrystallization, a large number of studies have shown that there is a definite function 
relationship between the average grain size $d$ and the $Z$ parameter, and there are two main models:

(1) Sellars model:

$d=C Z^{-n_{d}}$

where $c, n_{\mathrm{d}}$ are constants

(2) Sekine model:

$d=\log a Z^{-n}$,

where $\alpha, n$ are constants.

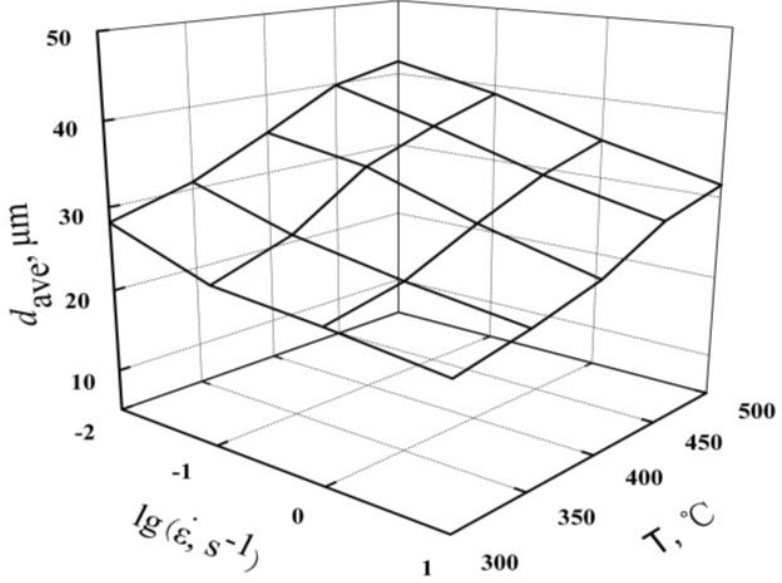

Fig. 3. Relationship between average grain size and deformation temperature $\backslash$ strain rate

The model of the average grain size was established according to the Sellars model. The average grain size $\left(d_{\text {ave }}\right)$ is linearly regressed with the $Z$-parameters to establish the relationship between them:

$\ln d_{\text {ave }}=-0.05 \ln Z+4.79 ; \quad R=0.99$.

It can be seen that the linear correlation coefficient $(\mathrm{R})$ is greater than $R_{0.01}(10)=0.82$, indicating that the regression equation is highly significant. Fig. 4 shows the relationship between the average grain size and the $Z$-parameter.

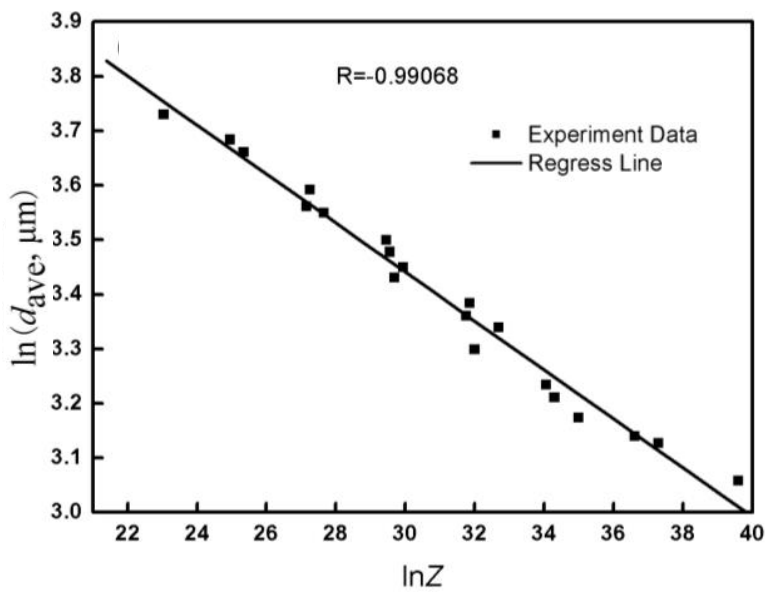

Fig. 4. Relationship between the average grain size and $\ln Z$

It can be seen that the average grain size after the hot deformation increases with the decrease of the $Z$ value (the decrease of the strain rate or the increase of the deformation temperature). The experimental data is well fitted to the predicted Eq. 13, which helps to predict the size of the deformed grains of the alloy based on the deformation conditions. It is consistent with the observation of microstructure in Fig. 2. If both the deformation temperature and the strain rate are changed at the same time, and the $Z$ value is guaranteed to be constant, the structure in which the average grain size is approximately close can be obtained. So it is possible to predict the structural characteristics (such as the grain size) of the alloy in a certain strain rate and deformation temperature, which can provide a reasonable experimental basis for the optimization and control of the deformation condition.

The average grain size increases with the decrease of the $\mathrm{Z}$ value (the decrease of the strain rate or the increase of the deformation temperature), which can be explained from the following two aspects [13-15].

Firstly, according to the theory of metal plastic deformation heat activation, the material enters the steadystate rheological stage, mainly through the cross-slip of the screw dislocation and the climb of the edge dislocation to achieve softening. The essence of alloy deformation is mainly the dynamic equilibrium between the proliferation of the dislocation and the annihilation and recombination of the dislocation caused by the interaction. If the orientation difference of the sub-grain in the deformed structure of the alloy, the sub-grain size and the dislocation density remain substantially the same, the alloy undergoes a process of "repeating the polygonalization" [16]. With the decrease of the strain rate or the increase of the deformation temperature (the decrease of the $\ln Z$ value), the heat activation capacity of the atom is enhanced, that is, the number of thermal activation in the unit strain condition is increased. When the strain generates many vacancies, it can cause the climb to occur quickly. The reorganization or cancellation between the dislocations can be carried out thoroughly, and the movable distance between the dislocations increases, so that the repetitive polygonal process can be carried out thoroughly, and finally the sub-grain structure of larger size is produced.

Secondly, the flow stress of the alloy during the deformation includes local stress $\sigma_{\mathrm{b}}$ (related to the material structure) and the stress $\sigma_{\mathrm{a}}$ required to ensure dislocation movement. Under the steady-state conditions, the flow stress is the sum of the instantaneous values of $\sigma_{\mathrm{a}}$ and $\sigma_{\mathrm{b}}$, and the relationship between the sub-grain size and the applied stress is established by $\sigma_{\mathrm{b}} . \sigma_{\mathrm{a}}$ can be expressed as a function related to the $Z$ value, and $\sigma_{\mathrm{b}}$ is a function that is closely related to the change of material structure, which is closely related to dislocation configuration, dislocation density and phase composition. During the hot compression process, with the decrease of the $\mathrm{Z}$ value, the heat activation capacity of the alloy is enhanced, the number of movable dislocations increases, and the dislocations cancel each other, causing the dislocation density to decrease [17]. As the number of thermal activation increases, the distance of the sub-grain boundary is increased, and the arrangement of the dislocation tends toward a simple and stable configuration direction. Therefore, the sub-grain size of the 3003 aluminum alloy after hot compression deformation increases when the $Z$ value decreases (strain rate decrease or deformation temperature increase). 


\subsection{Establishment of relationship model of the microstructure and properties}

The true stress-true strain curves in Fig. 1 show that the steady-state flow stress increases with the increase of the strain rate or the decrease of the deformation temperature, that is, the steady-state flow stress is closely related to the deformation condition ( $Z$ parameter). The deformation conditions will also affect the thermal deformation structure (grain size) [18]. Therefore, it is necessary to establish the relationship between macroscopic mechanical properties (steady flow stress) and thermal deformation structure. The linear regression of the thermal deformation steady-state flow stress $\left(\sigma_{\mathrm{s}}\right)$ and the average grain size $\left(d_{\text {ave }}\right)$ can be obtained.

$\ln \sigma_{s}=-2.10 \ln d_{\text {ave }}+11.02 ; \quad R=0.95$.

The linear correlation coefficient $R$ is greater than $R_{0.01}(10)=0.82$, indicating that the regression Eq. 14 is highly significant. The relationship between the steady-state flow stress and the average grain size is shown as Fig. 5.

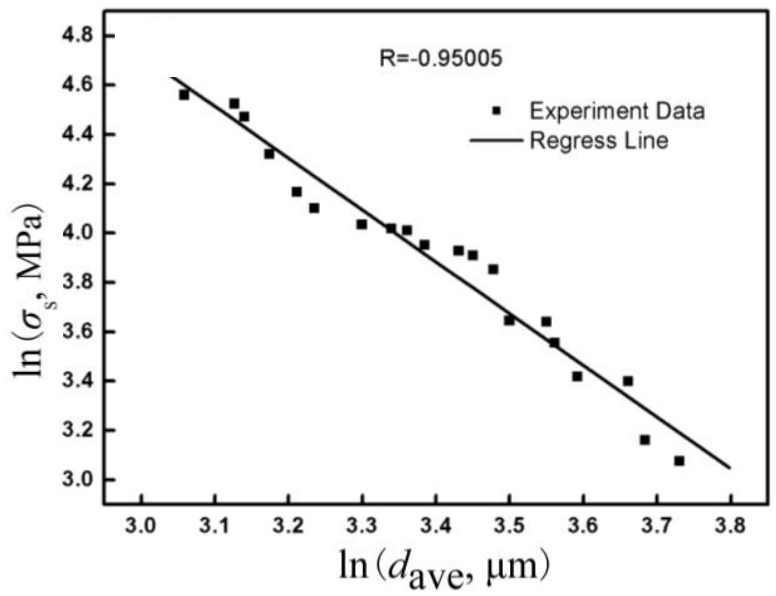

Fig. 5. Relationship between the average grain size and the steady - state flow stress

It can be seen that the experimental data fit well with the regression line. The flow stress of the alloy is closely related to the deformed grain size. The steady-state flow stress increases with the decrease of the average grain size, which is in accordance with the Hall-Petch relation, that is, the smaller the grain size is, the greater the steady-state flow stress is. Eq. 14 shows quantitatively that the microstructure plays a key role in the mechanical properties of the alloy. Therefore, in order to obtain the ideal thermal deformation structure, the hot deformation process parameters can be adjusted according to Eq. 13, and the rolling capacity of the equipment can be reasonably determined by Eq. 14 .

\subsection{Effect of hot deformation conditions on microhardness}

The microstructure changes after the specimen is deformed at high temperature. It has undergone the changes of work hardening, dynamic softening and dislocation configuration, which will affect the performance of the alloy. Therefore, the microhardness of the 3003 aluminum alloy after hot deformation is tested. The three-dimensional relationship diagram was established among the microhardness, the deformation temperature and the strain rate, as shown in Fig. 6.

It can be seen that the microhardness of the alloy after hot compression deformation increases with the decrease of deformation temperature and the increase of strain rate.

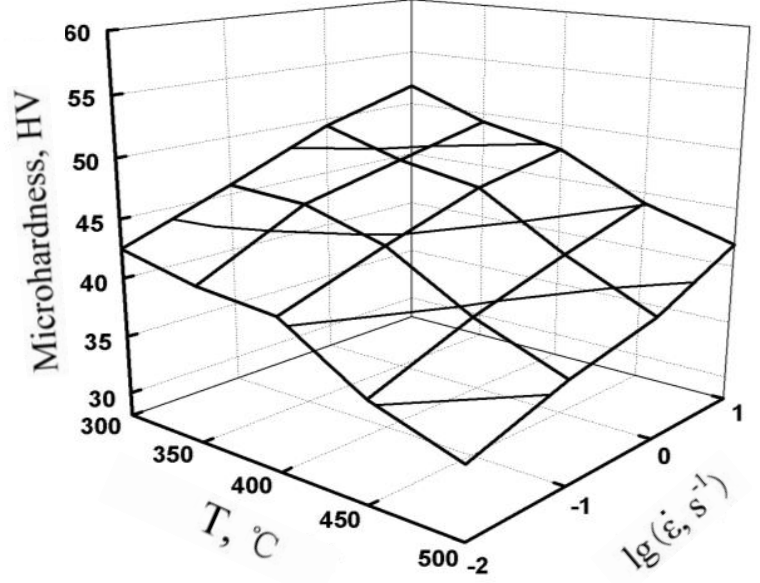

Fig. 6. The three $\quad-$ dimensional relationship among microhardness, deformation temperature and strain rate

If the deformation temperature decreases, the microhardness also decreases, because only a small amount of dynamic recrystallization occurs at low temperature. The microhardness increases with the increase of the strain rate. It is due to the increase of the strain rate, the storage energy of the alloy increases, which is manifested in the increase of the microhardness of the alloy [19].

According to the above analysis, the microhardness is closely related to the deformation condition. The relationship between microhardness $(H V)$ and deformation condition $(\ln Z)$ is established by a linear regression.

$f(H V)=1.06 \ln Z+10.18 ; R=0.97$.

The linear correlation coefficient $R$ of Eq. 15 is greater than $R_{0.01}(10)=0.8233$, indicating that the regression equation is highly significant. The relationship between the microhardness and the deformation condition is shown as Fig. 7.

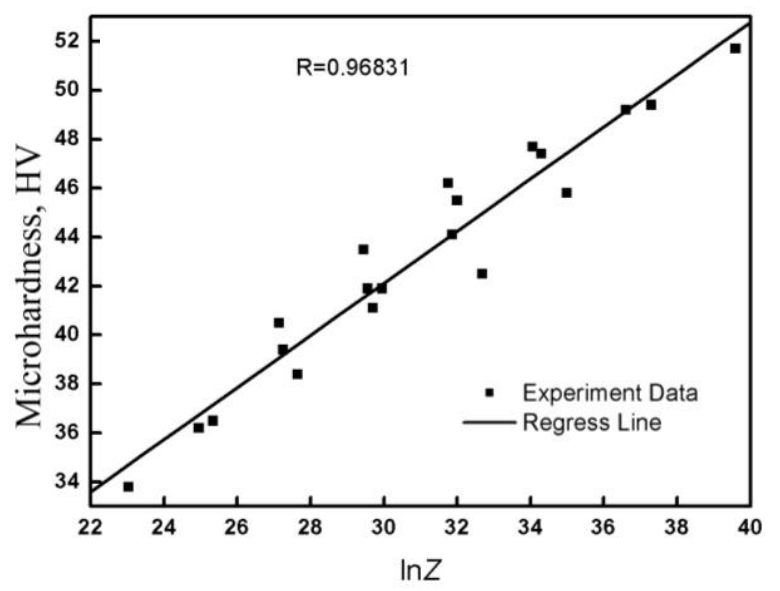

Fig. 7. Relationship between microhardness and $Z$ parameters

It can be seen that the microhardness is linearly related to $\ln Z$, that is, the microhardness increases with the increase of the $Z$ value. The properties of the alloy can be predicted 
based on the hot deformation conditions. By changing the strain rate or deformation temperature, the desired material properties can be obtained.

\subsection{Relationship between microhardness and hot deformation grain size}

The microhardness difference is related to the grain size after the hot deformation. The relationship among the microhardness, the grain size and the strain rate can be established. The results are shown in Fig. 8.

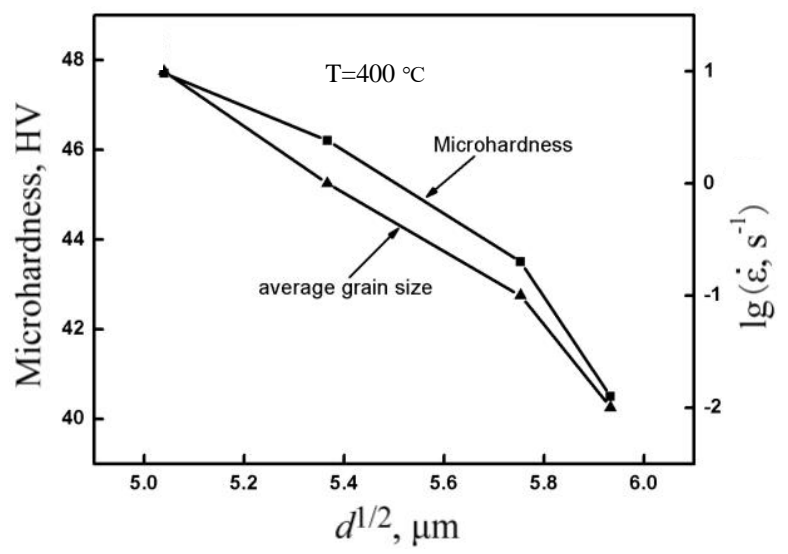

Fig. 8. Relationship among microhardness, average grain size and strain rate

The microhardness increases as the grain size decreases, since the relationship between the microhardness $(H V)$ and the yield strength $\left(\sigma_{\mathrm{y}}\right)$ of the material is [20]:

$H V=\mathrm{C} \sigma_{y} \propto \sigma_{y}$.

If the microhardness uses the international unit system, the constant $C \approx 3$.

The grain size $d$ and the yield strength are in accordance with the Hall-Petch relation [21]:

$\Delta \sigma_{y}=\mathrm{k} \Delta \frac{1}{\sqrt{d}} \propto \Delta \frac{1}{\sqrt{d}}$,

ehere $\mathrm{k}$ is the material constant.

It can be seen from the Eq. 16 and Eq. 17 that the smaller the average grain size, the higher the microhardness. It is consistent with the observations in Fig. 8.

\section{CONCLUSIONS}

1. The alloy undergoes DRX and is more likely to deform under high temperature and low strain rate conditions. A hot deformation constitutive equation of the alloy was established.

2. The average grain size of 3003 aluminum alloy during hot deformation increases with the decrease of $Z$ value, and the relationship model between them is established, which can be used to predict the hot deformation structure.

3. The steady-state flow stress increases with the decrease of the average grain size, which are in line with HallPetch relationship.

4. The microhardness of 3003 aluminum alloy after hot deformation increases with the decrease of deformation temperature and the increase of strain rate. There is a positive linear relationship between microhardness and $\ln Z$, and the microhardness increases as the grain size decreases.

\section{Acknowledgments}

The authors would like to acknowledge the financial support from Fujian Natural Science Foundation (2017J01156, 2017J01083), transportation science and technology project of Fujian Province (201810), Science and Technology Project of Fujian Education Department (JA15659), and materials nearly net forming and digital manufacturing technology service team of Fujian Chuanzheng Communications College of China.

\section{REFERENCES}

1. Jr, A.M.J., Prokofiev, E., Triques, M.R.M., Roche, V., Botta, W.J., Kiminami, C.S., Raab, G.I., Valiev, R.Z., Langdon, T.G. Effect of Cold Rolling on the Structure and Hydrogen Properties of Az91 and Am60D Magnesium Alloys Processed by ECAP International Journal of Hydrogen Energy 42 (34) 2017: pp. 21822-21831.

https://doi.org/10.1016/j.ijhydene.2017.07.118

2. Konkova, T., Mironov, S., Korznikov, A., Korznikova, G., Myshlyaev, M.M., Semiatin, S.L. Grain Structure Evolution during Cryogenic Rolling of Alpha Brass Journal of Alloys and Compounds 629 2015: pp. 140-147. https://doi.org/10.1016/j.jallcom.2014.12.241

3. Koptseva, N.V., Nikitenko, O.A., Efimova, Yu.Yu. Study of Microstructure Formation of Carbon Steel under HighSpeed and Multicycle Hot Plastic Compressive Deformation Using a Gleeble 3500 Unit Metal Science Heat Treatment 58 (5-6) 2016: pp. 318-323. https://doi.org/10.1007/s11041-016-0010-z

4. Olakanmi, E.O., Cochrane, R.F., Dalgarno, K.W. A Review on Selective Laser Sintering/Melting (Sls/Slm) of Aluminium Alloy Powders: Processing, Microstructure, and Properties Progress in Materials Science 74 2015: pp. $401-477$.

https://doi.org/10.1016/j.pmatsci.2015.03.002

5. Senkov, O.N., Senkova, S.V., Woodward, C. Effect of Aluminum on the Microstructure and Properties of Two Refractory High-Entropy Alloys Acta Materialia 68 2014: pp. $214-228$ https://doi.org/10.1016/j.actamat.2014.01.029

6. Nes, E., Marthinsen, K. Modeling the Evolution in Microstructure and Properties During Plastic Deformation of f.c.c.-Metals and Alloys - An Approach Towards A Unified Model Materials Science and Engineering: A 322(1-2) 2002: pp. $176-193$. https://doi.org/10.1016/S0921-5093(01)01130-3

7. Bouaziz, O., Allain, S., Scott, C.P., Cugy, P., Barbier, D. High Manganese Austenitic Twinning Induced Plasticity Steels: A Review of the Microstructure Properties Relationships Current Opinion in Solid State and Materials Science 15 (4) 2011: pp. 141-168. https://doi.org/10.1016/j.cossms.2011.04.002

8. Chen, G., Fu, G., Wei, T., Cheng, C., Wang, J., Wang, H. Establishment of Dynamic Recrystallization State Diagram of Hot Deformation for 3003 Aluminum Alloy Materials and technology 52(3) 2018: pp. 112-120. https://doi.org/10.17222/mit.2017.176 
9. Chen, G., Fu, G., Wei, T., Cheng, C., Lin, S., Song, L. Effect of Melt Treatment on Microstructure and Mechanical Properties of aa3003 Aluminum Alloy Materials and Technology 52 (5) 2018: pp. 214-223. https://doi.org/10.17222/mit.2017.207

10. Chen, G., Fu, G., Lin, S., Cheng, C., Yan, W., Chen, H. Simulation of Flow of 3003 Aluminum Alloy under Hot Compressive Deformation Metal Science and Heat Treatment $54(11-12)$ 2013: pp. 623-627. https://doi.org/10.1007/s11041-013-9560-5

11. Lee, M.G., Kim, S.J. Elastic-Plastic Constitutive Model for Accurate Springback Prediction in Hot Press Sheet Forming Metals and Materials International 18 (3) 2012: pp. $425-432$. https://doi.org/10.1007/s12540-012-3007-1

12. Etaati, A., Dehghani, K., Ebrahimi, G.R., Wang, H. Predicting the Flow Stress Behavior of Ni-42.5Ti-3Cu during Hot Deformation Using Constitutive Equations Metals and Materials International 19 (1) 2013: pp. 5-9. https://doi.org/10.1007/s12540-013-1002-9

13. Yin, F., Hua, L., Han, X. Microstructural Modeling and Simulation for Gcr15 Steel during Elevated Temperature Deformation Materials \& Design 55 2014: pp. 560-573. https://doi.org/10.1016/j.matdes.2013.10.042

14. Chen, G., Fu, G., Chen, H., Cheng, C., Yan, W., Lin, S. Optimization of a Hot Deformation Process of the 3003 Aluminum Alloy by Processing Maps Metals and Materials International 18 (5) 2012: pp. 813-819. https://doi.org/10.1007/s12540-012-5010-y

15. Yang, Q.Y., Yang, D., Zhang, Z.Q., Cao, L.F., Wu, X.D., Huang, G.J., Liu, Q. Flow Behavior and Microstructure Evolution of 6A82 Aluminium Alloy with High Copper Content during Hot Compression Deformation at Elevated Temperatures Transactions of Nonferrous Metals Society of China 26(3) 2016: pp. 649-657.
https://doi.org/10.1016/S1003-6326(16)64154-7

16. Chen, G., Fu, G., Chen, H., Yan, W., Cheng, C., Zou, Z. Comparative Study of the Influence of Various MeltTreatment Methods on Hot Deformation Behavior of $3003 \mathrm{Al}$ Alloy Metals and Materials International 18 (1) 2012: pp. $129-134$. https://doi.org/10.1007/s12540-012-0015-0

17. Chen, G.Q., Fu, G.S., Wei, T.Y., Cheng, C.Z., Wang, H.S., Wang, J.D. Effect of Initial Grain Size on the Dynamic Recrystallization of Hot Deformation for 3003 Aluminum Alloy Metals and Materials International 24 (4) 2018: pp. $1-9$. https://doi.org/10.1007/s12540-018-0093-8

18. Chen, G., $\quad$ Fu, G., $\quad$ Yan, W., Cheng, C., Zou, Z. Mathematical Model of Dynamic Recrystallization of Aluminum Alloy 3003 Metal Science and Heat Treatment 55 (3-4) 2013: pp. 220-225. https://doi.org/10.1007/s11041-013-9609-5

19. Fan, X.B., He, Z.B., Lin, P., Yuan, S.J. Microstructure, Texture and Hardness of $\mathrm{Al}-\mathrm{Cu}-\mathrm{Li}$ Alloy Sheet during Hot Gas Forming with Integrated Heat Treatment Materials \& Design 94 2016: pp. 449-456. https://doi.org/10.1016/j.matdes.2016.01.001

20. Busby, J.T., Harsh, M.C., Was, G.S. The Relationship between Hardness and Yield Stress in Irradiated Austenitic and Ferritic Steels Journal of Nuclear Materials $336(2-3)$ 2005: pp. $267-278$. https://doi.org/10.1016/j.jnucmat.2004.09.024

21. Nagasaka, T., Yoshida, H., Fukumoto, K., Yamamoto, T., Matsui, H. Mechanical Properties of a High-Purity Fe-9Cr2W-0.1C Model Alloy for Low-Activation Ferritic Steels for Fusion Reactors Materials Transactions, JIM 41 (1) 2000: pp. $170-177$. https://doi.org/10.2320/matertrans 1989.41.170 